\title{
Towards a Green and Sustainable Manufacturing Planning and Control Paradigm Using APS Technology
}

\author{
Kenn Steger-Jensen ${ }^{1}$, Heidi Dreyer ${ }^{2}$, Hans-Henrik Hvolby ${ }^{1}$, and Ola Strandhagen ${ }^{2}$ \\ ${ }^{1}$ Centre for Logistics, Department of Mechanical and Manufacturing Engineering, \\ Aalborg University, Fibigerstrede 16, 9220 Aalborg, Denmark \\ ${ }^{2}$ Department of Production and Quality Engineering, NTNU, \\ S P Andersensvej 5, Trondheim, Norway \\ $\{\mathrm{hhh}, \mathrm{kenn}\}$ @celog.dk, \\ \{heidi.c.dreyer, ola.strandhagen\}@ntnu.no
}

\begin{abstract}
This research aims at integrating a green perspective into manufacturing operations of companies through a new sustainable performance objective. The paper highlights the current trends in green and sustainable manufacturing and lines up different options for supporting this in current Advanced Planning and Scheduling Systems. Finally, requirements for future APS functionality is presented.
\end{abstract}

Keywords: Green, Sustainable, Manufacturing, Planning, Advanced Planning and Scheduling Systems, APS; Optimisation.

\section{Introduction}

Manufacturing and production operations are considered the most substantial contributor to climate challenges and environmental degradation, for which reason manufacturing firms must be held responsible as well [1]. The basic initiatives in dealing with climate challenges and environmental degradation have until recently mainly been green investments, which by experts have been referred to as 'business-as-usual' investments nowhere near what is perceived adequate. According to the World Economic Forum new approaches are necessary for creating and ensuring economic growth, sustainability and a stable future [2]. One approach which is addressed in the literature and perceived as a necessity to achieve the environmental and sustainable goals, is changing businesses' manufacturing philosophy [1,3].

Changing a manufacturing philosophy entails a shift in the way production systems are operated and managed and contains strategies, principles and techniques on how to achieve one or more objectives. Historically, manufacturing philosophies have changed concurrently with the industrial evolution from the industrial revolution and Adam Smith's division of labor over the Lean and just-in-time principles derived in the early 20th century, to the quality revolution of the 1980s and the supply-chain revolution of the 1990s [4]. Along with the evolution in production philosophies, there has been a natural progression in the way operational performance have been 
evaluated, where the main focus in the early stages of the industrial revolution was primarily on cost [5]. As competition has grown, the subsequent manufacturing philosophies have expanded this view, describing trade-offs between what have later been defined as the five performance objectives; quality, speed, dependability, flexibility and cost $[5,6]$.

As indicated, environmental management has not been considered an integral entity of operational performance in any of the production philosophies [1]. Instead, environmental management was commenced in the 1970s as risk management with focus on waste and pollution. With profitability as a continued driver, the agenda of the 1980s and 1990s addressed product and process management to reduce waste and ensure reusability using life cycle assessments [1].

In recent years, as the industrial evolution has become more and more influenced by the deterioration of the environment, overflowing waste, and increasing levels of pollution, a new paradigm has emerged within the manufacturing philosophy literature [4]. According to Deif [7] we see the rise of a green manufacturing paradigm, which includes eco-efficient strategies, that consumes less material and energy, substituting to cleaner and renewable input materials, reduces unwanted outputs and converting output to inputs. It is the manufacturing managers' awareness of its the production/product impact on the environment and the implementation of the green aspects into the planning and control models which are now necessary if realizing the green objectives in practice.

\section{Literature Study}

The sustainability of the industrial sector has become one of the most significant societal, political and business issues due to the fact that the manufacturing sector has a huge impact on the environment, economy and the quality of human life. The focus on the impact of manufacturing and supply chain activities including logistics and transportation has captured a huge academic and industrial interest which has led to significant contributions regarding figures and measures [8,9], concepts and strategies and methodologies and tools such as Life-Cycle Assessment (LCA) and Corporate Social Responsibility (CSR). Since first formulated in the Bruntland report in 1987 [10] it seems like the literature agrees on the understanding of sustainability as being the industrial sector's ability to create its outcome in a way that minimizes the impact on the environment, within secure social and ethical condition and contribute to economy and value creating [11].

Looking into the literature that focus on the negative externalities from the manufacturing industry it is the toxic chemicals, waste, energy and water consumption and greenhouse gas emissions and carbon footprint which is the main negative environmental impact from the industry $([8,12,13]$. According to the U.S. Toxic Release Inventory [14] the manufacturing industry is the second largest contributor in US of air emission, surface water discharges, land release and underground injections are the toxic chemicals [8]. Furthermore the industry generates a large amount of waste, mainly in the form of solid and water waste but also other categories such as materials, and the amount of waste is more than the sum of all other sectors combined. 
The energy consumption is high and is mainly supplied from fossil fuels which contain various polluting elements such as carbon, sulfur and nitrogen that causes greenhouse gases and global warming. With this impact on the environment, and, manufacturers' profitability, the importance of improving the environmental performance is high.

Deif [7] considers sustainability to be the concept and strategy while green manufacturing is the methodology, toolset and the way to dispose sustainability. Green manufacturing is regarded as the first step towards sustainable production and the ability to develop advanced manufacturing capabilities by involve the design and engineering activities in product development and/or the operations of production is critical for improving the environmentally performance of the manufacturing industry [15]. According to Deif [7] the existing literature consists of two types of contributions.

- The first type provides knowledge about the concept of green manufacturing covering topics as waste reduction activities, elimination of causal factors, and, green productivity measures, business models for using new material technologies and the use of sustainability information in decision support.

- The second category is analytical tools and methods that have been developed in order to realize green manufacturing at different levels. Tools for product/process design analyses such as life cycle assessment (LCA) and life cycle costing (LCA) used to evaluate the environmental impact of assets over the entire life cycle and Corporate social responsibility (CSR) used for taking the responsibility for the impact of their activities on customers, suppliers, employers, shareholders, community and the environment in all aspect of their operations.

Important contributions have been made but interestingly very few studies seem to have focused on operations management and how production is planned and controlled and how the green elements actually could be taken into consideration in the higher and lower production planning levels. There is one exception and that is the work by Melnyk et al [16], who has developed a tool that integrates environmental concerns into the material planning activities. By using this kind of tools one does not only make managers aware of the environmental and emission effects associated with the production strategy, plan and schedule, it also triggers action such as changing the plan and the schedule. We have identified a gap in the current literature and a need for developing tools that allow managers to embed green aspects into the higher and lower production and control planning levels and by doing so to be able to take the right decisions in order to actually become more sustainable by simultaneously taking environmental and profit optimizing aspects into account.

\section{Towards a Green Manufacturing Planning and Control Paradigm}

Pursuing sustainability as a performance objective for manufacturing operations requires primary changes to the manufacturing planning and control system. This is chosen as a point of departure because such systems contain all essential activities that are used within a company for planning and controlling its manufacturing operations [17]. 
The main goal of developing a "green" manufacturing planning and control framework is to include green parameters into the planning process alongside materials and resources (typically machines and operators) with the aim of reducing the amount of green sources used such as materials, energy and water. Melnyk [16] includes materials waste in the materials requirement planning (MRP) process by implementing a "Bill-Of-Waste", but although their paper is titled "Green MRP" the goal is not to reduce waste but merely to identify the waste created. In the literature study we have identified a list of authors dealing with Green Supply Chains, Green Manufacturing and Green Planning. However, none of these studies discuss how to include green parameters in the planning process.

Traditional enterprise resource planning (ERP) systems do not optimize materials and resource usage but merely calculate the requirement for materials and resources. Therefore, ERP-systems are not able to support our definition of "Green Planning" in terms of optimized planning taking all resources such as materials, operators, energy and water into consideration. This is, however, partly possible in advanced planning and scheduling (APS) systems. In the following we will discuss how this is possible in existing implementations of APS and how to bring APS further towards green manufacturing.

\subsection{Advanced Planning and Scheduling (APS) Systems}

APS systems use complex mathematical algorithms to plan and schedule production within specified constraints and to derive optimal product-mix solutions. APSsystems aim at reducing costs of goods sold and to increase customer satisfaction by making the right products at the right times, using an optimal combination of manufacturing resources. APS systems are hence able to generate far more realistic and reliable production plans than ERP systems [18,19].

When multiple objectives exist in a manufacturing environment, and most of these are in conflict with each another, an approach is needed for modelling and evaluating the trade-off among the conflicting objectives. Here two options exist: Constraint based planning and optimization. The two approaches are discussed in the following.

\subsection{Constraint Based Planning}

Constrained based planning is based on hard and soft (or goal) constraints. Its distinguished feature is that the objectives can be stated as minimising deviations from pre-specified goals. Hard constraints are not overruled, whereas soft constraints are overruled, if necessary. As no plan optimisation objectives or criteria are considered this option produces a feasible but not necessarily an optimal plan. Therefore, APSsystems use a hidden plan objective function, which drives the planning and trade-off among the soft constraints. The hidden plan objective function is defined as minimizing plan cost.

It is possible to select one and only one "domain", either demand or supply, to be a hard constraint. If the demand domain is selected as a hard constraint, customer due dates are enforced while material and capacity availability become soft constraints. 
If the supply domain is selected as a hard constraint, the capacity constraints are enforced, while demand due dates might be overruled. At the same time there is an option to determine whether the constrained plan enforces material, resource capacity or both. Resource capacity constraints are subdivided into operation resources, sourcing resources (supplier, inventory) and transportation resources.

In addition to hard and soft constraints it is possible to use business rules and demand priorities. Business rules are part of the master data and used as explicit decisions made on the supply domain when there are more options to choose among in the plan generation. Business rules are ranked by use of priorities of given topics such as sourcing of capacity, supplier and items. As an example, material requirements are fulfilled from rank 1 suppliers before sourcing from lower ranking suppliers independent of costs.

Rules play an important role in constraint based planning systems by avoiding the traditional (time-consuming) re-planning and re-scheduling after plan generation. If environmental factors are included in the master data and used as well in the business rules and demand priorities it will be possible to support green planning parameters.

\subsection{Optimisation}

Optimised plans are generated based on plan objectives, penalty factors and constraints beside the hard and soft constraints. The constraint-based rules are exchanged with decision variables and penalty factors, instead of the hidden object function and business rules and demand priorities. To optimise a total plan the APS engine needs one single mutual measure - money - in terms of costs and on profits. In the optimisation the soft constraints might be overruled if this reduces the total costs. For example, demand priority and supplier allocation ranks could be overruled to reach the best profit. If a rank 2 supplier results in lower cost than a rank 1 supplier does, orders will be allocated to the rank 2 supplier(s).

In connection with the objective function, three parameters can be weighted: ontime delivery, inventory turns and plan profit. Besides the objectives, a number of decision variables can be used to achieve the wanted business goals. A planner can use multiple objective criteria to evaluate plans for an unlimited number of decision variables. The decision variables are almost the same as the rules used in CBP without objectives, but in CBP with objectives there are alternative and substitutional conditions considered according to bills and routes.

The decision variables are all time-phased and include supplier sources, routings, BOM's, items, resources, production and purchasing quantities, transportation and safety stock levels. The optimisation seeks the best combination of these decisions.

The optimisation satisfies weighted objectives and takes the penalty factors related to these decision variables into consideration. The following penalty cost factors are used explicitly in relation to decision variables: late demand, safety stock level, exceeding material, exceeding resource capacity and exceeding transportation resource capacity. A planner enters percentages to indicate how important it is that those outcomes do not occur in your plan. The optimisation process drives penalties out of the solution, and tends to drive the most costly penalty factors out first. A high degree of 
accuracy in setting penalty factors is not as important as the relationship between penalty factors.

When the APS system makes decisions to avoid late demand, it will place higher priority to keeping large sales orders on time. When the penalty for late demand is higher than the penalty for exceeding resource capacity (factor times work order resource cost), the solution will tend to plan overtime work in order to avoid late delivery. In general, all penalty factors work this way.

\subsection{Including Green Objectives}

The optimised planning as described above is based on a cost perspective, whereas the constraint based planning is based on business rules and demand priorities. When performing its optimization, the APS system has one unique measure: costs (\$). One can discuss whether it is possible to measure green (environmental) factors in terms of costs. Some measures, such as water and $\mathrm{CO} 2$, may be directly linked to costs whereas outlet of detergents may have specific requirements as to what level is accepted by the government. The latter (here defined as "environmental related factors") is therefore more difficult to include in a financial-based optimization.

Current APS systems have some opportunities for supporting green planning. The most obvious solution is to include green factors in the bill-of-materials (BOM) and the routings. This could for example be done by adding a "CO2" or "WATER" component in the BOM and an "ENERGY" resource in the routing. As APS can handle alternative routings and BOM's it would be possible to offer some kind of environmental optimisation. This approach works for cost related factors but not for environmental related factors. Currently, APS enables a configuration of the plan optimization in terms of weighting the following objectives:

- $\quad$ Plan profit

- Inventory turns

- On-time delivery

One obvious improvement option is to add one more objective to satisfy environmental issues, especially to enable an optimisation of the non-cost related factors. In the following table the options in current APS systems are highlighted.

\begin{tabular}{|l|l|l|}
\hline & $\begin{array}{l}\text { Constraints based } \\
\text { Planning }\end{array}$ & Optimization based Planning \\
\hline $\begin{array}{l}\text { Objectives/ } \\
\text { Decisions } \\
\text { variables }\end{array}$ & $\begin{array}{l}\text { Hidden objective func- } \\
\text { tion containing cost } \\
\text { related to pollution } \\
\text { factors: }\end{array}$ & $\begin{array}{l}\text { Profit based optimisation: } \\
\text { As for CBP, requirements on environment } \\
\text { factors is need in the master data }\end{array}$ \\
& $\begin{array}{l}\text { Requirement on envi- } \\
\text { ronment factors (air, } \\
\text { water and energy) is } \\
\text { need in the master data, } \\
\text { to calculate the sustain- } \\
\text { ability }\end{array}$ & $\begin{array}{l}\text { Sustainability based optimisation: } \\
\text { pot possible today, but environment im- } \\
\text { pact of pollution factors in the current ob- } \\
\text { ject function is need or a unique objective } \\
\text { for total pollution of environment in the } \\
\text { object function is need to calculate the } \\
\text { sustainability. }\end{array}$ \\
\hline
\end{tabular}




\begin{tabular}{|l|l|l|}
\hline Constraints & $\begin{array}{l}\text { Demand priorities: } \\
\text { Where delivery to cus- } \\
\text { tomer contain less pollu- } \\
\text { tion factors }\end{array}$ & $\begin{array}{l}\text { Hard constraints: } \\
\text { As today, but since environment impact of } \\
\text { pollution factors is not discrete and unique } \\
\text { defined, they are modelled as resources in } \\
\text { the master data. }\end{array}$ \\
\cline { 2 - 4 } & $\begin{array}{l}\text { Business Rules: } \\
\text { Where sourcing contain } \\
\text { less pollution factors }\end{array}$ & $\begin{array}{l}\text { Soft constraints: } \\
\text { Not possible today, since environment } \\
\text { impact of pollution factors is not discrete } \\
\text { and unique defined. }\end{array}$ \\
\hline Penalty & $\begin{array}{l}\text { None as constraints are } \\
\text { not overruled }\end{array}$ & $\begin{array}{l}\text { Late demand and Exceeding material, } \\
\text { inventory, transportation, machine and } \\
\text { labour capacity. } \\
\text { As today, but modelled as resources in the } \\
\text { master data. }\end{array}$ \\
\cline { 2 - 4 } & $\begin{array}{l}\text { Sustainability based penalty: } \\
\text { Not possible today, since environment } \\
\text { impact of pollution factors is not discrete } \\
\text { and unique defined. }\end{array}$ \\
\hline
\end{tabular}

\section{Conclusion}

The effective use of Advanced Planning and Scheduling Systems is a step in the right direction towards generating more realistic and reliable plans. However, optimisation and its objectives and penalty factors within manufacturing systems do not yet support 'green planning' from a sustainability point of view. The optimised plan is based on a cost perspective, which does not always lead to a sustainable plan whereas the constraint based plan is based on business rules and priority, which for the current release is too simple for green planning.

The planner has to know a lot about green production conditions and cost structures to be capable of using optimization. The optimisation is based on a data structure, which does not directly support green planning parameters. The gap between current models and methods in APS systems and models and methods directly supporting green planning is an area for further research.

Acknowledgements. The authors would like to express their gratitude to the Danish Business Innovation Fund for supporting the project which this research is a part of and to Chris Martin for assistance in editing. 


\section{References}

1. Beamon, B.M.: Designing the green supply chain. Logistics Information Management 12(4), 332-342 (1999)

2. World Economic Forum, "The Green Investment Report The ways and means to unlock private finance for green growth" (2013)

3. de Burgos Jiménez, J., Lorente, J.: Environmental performance as an operations objective. International Journal of Operations \& Production Management 21(12), 1553-1572 (2001)

4. Srivastava, S.K.: "Green supply-chain management - A state-of-the-art literature review". International Journal of Management Reviews (2007)

5. Sarkis, J., Qinghua, Z., Kee-Hung, L.: An organizational theoretic review of green supply chain management literature. International Journal - Production Economics 130(2011), $1-15(2010)$

6. Slack, N., Chambers, S., Johnston, R.: Operations Management. 5. Prentice Hall (2007)

7. Deif, A.M.: A system model for green manufacturing. Journal of Cleaner Production 19, 1553-1559 (2011)

8. Dornfeld, D.A.: Green Manufacturing: Fundamentals and Applications. Springer, New York (2013)

9. Bunse, K., Vodicka, M., Schönsleben, P., Brülhart, M., Ernst, F.: Integrating energy efficiency performance in production management - gap analysis between industrial needs and scientific literature. Journal of Cleaner Production 19(6-7), 667-679 (2011)

10. Brundtland Commission, i.e. World Commission on Environment and Development, WCED (1993)

11. Manzan, R., Miyake, D.: A Study on Alternative Approaches to Instill Environmental Concerns in the Domain of Production Management of Industrial Firms. Journal of Technology management \& Innovation 8(3), 198-207 (2013)

12. Despeisse, M., Ball, P.D., Evans, S., Levers, A.: Industrial ecology at factory level - a conceptual model. Journal of Cleaner Production 13, 30-39 (2012)

13. Garetti, M., Taisch, M.: Sustainable manufacturing: trends and research challenges. Production Planning and Control 23(2-3), 88-104 (2012)

14. US Toxic Release Inventory Program. Last accessed (June 2014),

http: //www2 .epa.gov/toxics-release-inventory-tri-

program/2011-tri-national-analysis

15. Klassen, R.D., Whybark, D.C.: The impact of environmental technologies on manufacturing performance. Academy of Management Journal 42(6), 599-614 (1999)

16. Melnyk, S.A., Sroufe, R.P., Montabon, F.L., Hinds, J.: International Journal Production Research 39(8), 1559-1573 (2001)

17. Silver, E., Pyke, D., Petersen, R.: Inventory management and production planning and scheduling. John Wiley \& Sons (1998)

18. Jacobs, F., Weston, F.C.: Enterprise resource planning (ERP) - A brief history. Journal of Operations Management 31, 357-363 (2007)

19. Hvolby, H.-H., Steger-Jensen, K.: Technical and Industrial Issues of Advanced Planning and Scheduling (APS) Systems. Computers in Industry 61(9), 845-851 (2010) 